\title{
Generation and analysis of expressed sequence tags from $\mathrm{NaCl}$-treated Glycine soja
}

Email: Wei Ji - iwei_j@hotmail.com; Yong Li - Yon_Li@hotmail.com; Jie Li - lijie1972@hotmail.com; Cuihong Dai - daicuihong@hotmail.com; Xi Wang - lagow@163.com; Xi Bai - baixi75@hotmail.com; Hua Cai - small-big@sohu.com; Liang Yang - yj12071109@sohu.com; Yan-ming Zhu* - ymzhu2001@hotmail.com

* Corresponding author †Equal contributors

Published: 22 February 2006

BMC Plant Biology 2006, 6:4 doi:10.1 186/147|-2229-6-4
Received: 25 October 2005

Accepted: 22 February 2006

This article is available from: http://www.biomedcentral.com/l47|-2229/6/4

(c) 2006 Ji et al; licensee BioMed Central Ltd.

This is an Open Access article distributed under the terms of the Creative Commons Attribution License (http://creativecommons.org/licenses/by/2.0), which permits unrestricted use, distribution, and reproduction in any medium, provided the original work is properly cited.

\begin{abstract}
Background: Salinization causes negative effects on plant productivity and poses an increasingly serious threat to the sustainability of agriculture. Wild soybean (Glycine soja) can survive in highly saline conditions, therefore provides an ideal candidate plant system for salt tolerance gene mining.

Results: As a first step towards the characterization of genes that contribute to combating salinity stress, we constructed a full-length cDNA library of Glycine soja (50/09) leaf treated with $150 \mathrm{mM}$ $\mathrm{NaCl}$, using the SMART technology. Random expressed sequence tag (EST) sequencing of 2,219 clones produced 2,003 cleaned ESTs for gene expression analysis. The average read length of cleaned ESTs was $454 \mathrm{bp}$, with an average GC content of $40 \%$. These ESTs were assembled using the PHRAP program to generate 375 contigs and 696 singlets. The resulting unigenes were categorized according to the Gene Ontology (GO) hierarchy. The potential roles of gene products associated with stress related ESTs were discussed. We compared the EST sequences of Glycine soja to that of Glycine max by using the blastn algorithm. Most expressed sequences from wild soybean exhibited similarity with soybean. All our EST data are available on the Internet (GenBank_Accn: DT082443 DT084445).

Conclusion: The Glycine soja ESTs will be used to mine salt tolerance gene, whose full-length cDNAs will be obtained easily from the full-length cDNA library. Comparison of Glycine soja ESTs with those of Glycine max revealed the potential to investigate the wild soybean's expression profile using the soybean's gene chip. This will provide opportunities to understand the genetic mechanisms underlying stress response of plants.
\end{abstract}

\section{Background}

Environmental factors that impose water-deficit stress, such as drought, salinity and extreme temperatures, place major limits on plant productivity [1]. It is a problem that deserves global attention. In particular, increasing soil salinization has necessitated the identification of crop traits/genes that confer resistance to salinity. Traditional breeding strategies are limited by the complexity of stress tolerance traits, low genetic variance of yield components under stress conditions and the lack of efficient selection 


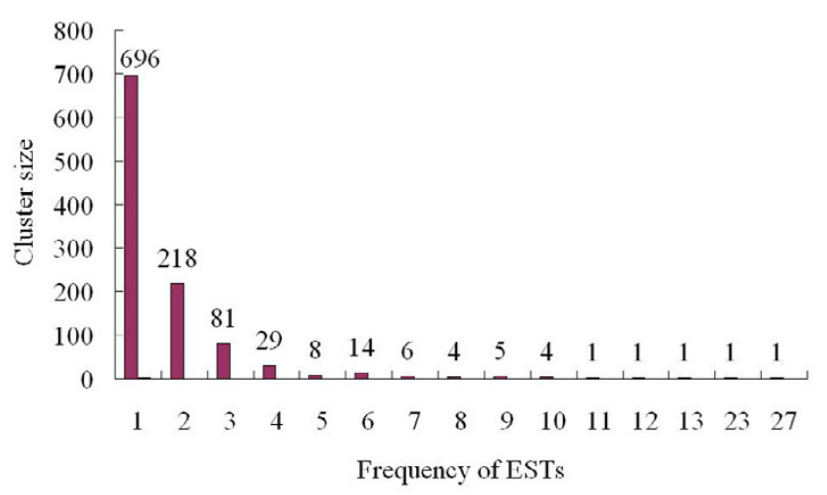

Figure I

Distribution and number of clustered sequences.

techniques [2]. With the great progress of molecular biology, introducing some functional genes of interest to crop plants by genetic engineering seems to be a shortcut to improve stress tolerance [3]. However, the approach has been limited by the lack of understanding of metabolic flux, compartmentation and function [4]. Thus, the integrative, whole genome studies of various stress-resistant mechanisms are needed [5,6]. A series of functional genomics strategies have emerged as required and the applications of these new technologies will accelerate the relevant research.

Expressed sequence tags (ESTs), which are generated by large-scale single-pass sequencing of randomly picked cDNA clones, have proven to be an efficient and rapid means to identify novel genes [7]. With many large-scale EST sequencing projects in progress and new projects being initiated, comparative genomics approaches are needed to assign putative functions to these cDNAs [8]. Such studies will present opportunities to accelerate progress towards understanding the genetic mechanisms underlying stress response of plants.

Glycine soja (50109) is one of the highly salt tolerant species that grows in coastal regions. The seeds were found to tolerate up to $0.9 \%$ of salt during germination stage, while Glycine max cannot grow well in regions where the salt concentration is $0.3 \%$ [9]. It is thus an ideal candidate plant for mining salt-tolerance genes.

In this study, single-pass sequences of randomly selected cDNA clones from a full-length cDNA library of Glycine soja leaf treated with $150 \mathrm{mM} \mathrm{NaCl}$ were obtained. The ESTs were classified into functional categories through comparisons with Glycine max, Arabidopsis and Oryza sativa genes in known databases. The potential roles of gene products associated with stress related ESTs were discussed.

\section{Results and discussion Generation of ESTs from Glycine soja subjected to salt stress}

The information provided by ESTs of randomly isolated gene transcripts generated under specific abiotic stress conditions provides an opportunity for gene discovery in addition to identifying the biochemical pathways involved in plant physiological responses [10]. Here, we describe ESTs obtained from salinity-induced cDNA library prepared from the leaves of the Glycine soja exposed to stress for a short period of time. Insert amplification of all random clones from cDNA library revealed inserts ranging between $500 \mathrm{bp}$ and $2000 \mathrm{bp}$, with an average size of $1250 \mathrm{bp}$. A total of 2,219 clones were sequenced, and 2,003 cleaned EST sequences were generated for further analysis after trimming off vector sequences and removing of sequences shorter than $100 \mathrm{bp}$ (GenBank_Accn: DT082443 DT084445). The average read-length of cleaned ESTs was $454 \mathrm{bp}$. The cleaned ESTs include 19365 'end sequences and 67 3'end sequences (Table 1). The average $\mathrm{G}+\mathrm{C}$ content of Glycine soja ESTs was $40 \%$, which is similar to that of soybean [11]. The 2003 ESTs were assembled into 375 contigs and 696 singlets (clusters) using the PHRAP program (Table 1). The frequency of EST distribution after clustering is shown in Fig. 1. Nine contigs had 10 or more ESTs, with the largest one containing 27 ESTs. Most contigs contained one to six ESTs. The redundancy level of EST collection was 65\%, which means that continued sequencing of cDNAs selected at random from our libraries still has considerable potential to uncover novel sequences.

\section{Comparisons of Glycine soja ESTs with those in Glycine max, Arabidopsis and Oryza sativa}

Blastn was used to compare the EST sequences of Glycine soja to Glycine max, Arabidopsis and rice. The E-value was set at 1e-30. Although the size of Glycine max Gene Index is smaller than the AGI and OGI, the sum of matching section between Glycine soja and Glycine max (3106) was far more than Glycine soja versus Arabidopsis or Glycine soja versus Oryza sativa (Table 2). Note that there is great difference in stress-tolerant characteristics between soybean and wild soybean, although they share a large amount of homologs in expressed sequences. This indicates that the discrepancy in stress responses may come from the subtle difference between the homologous sequences. It is therefore feasible to investigate the wild soybean's gene expression profile using the Affymetrix soybean chip.

In order to get more information about the expression pattern of Glycine soja ESTs, BLASTN was used to search against the Arabidopsis CDS from TAIR, and 244 ESTs were highly similar to genes from Arabidopsis. The corresponding Arabidopsis genes were searched for the expression data under salt stress since global expression profiling of the 
Table I: Glycine soja EST Summary

\begin{tabular}{ll}
\hline Total ESTs & 2219 \\
Total high-quality ESTs & 2003 \\
Success index (\%) & 90.3 \\
5'-end sequences & 1936 \\
3'-end sequences & 67 \\
Average insert size (bp) & 1250 \\
Average sequence size (bp) & 454 \\
Average GC content(\%) & 40 \\
Number of contigs & 375 \\
Number of singlets & 696 \\
Number of unigenes & 1071 \\
\hline
\end{tabular}

Arabidopsis was available from TAIR[12]. As a result, a total of 126 ESTs were predicted to be up-regulated in response to salt stress according to AtGenExpress, and may be induced by salt stress. This prediction will be confirmed by further analysis.

\section{Functional categorization of Glycine soja ESTs and Putative stress-regulated genes}

As shown in Tables 3 and Figure 2, all unigenes were classified according to terms of biological processes, molecular functions and cellular components, developed by the Gene Ontology Consortium [13] in Uniprot (EBI). These genes cover a broad range of the $\mathrm{GO}$ functional categories. However, due to the lack of gene products information, many transcripts cannnot be functionally categorized. These 'unknown' genes are likely the source of candidate salt-tolerant genes and further functional analysis will help elucidate their specific roles in salt tolerance [14].

We successfully classified 279 unigenes in terms of biological processes (Fig. 2A), 301 unigenes in terms of molecular function (Fig. 2B), and 262 unigenes in terms of cellular components. Since one gene product may be assigned to more than one GO terms, and one children term can fit into multiple parental categories, the total number of GO mappings in each of the three ontologies will exceed the number of genes.

A large proportion of genes were found to participate in the biological process of metabolism (69\%), followed by cell growth and/or maintenance (13\%). The accumula- tion of osmoprotectants by either altering metabolism or increasing transport is an important process of plants for the adaptation to environmental stress [15]. It has been reported that in Arabidopsis, salinity induces programmed cell death in primary roots and the plants produce secondary roots which function better under abiotic stress [16]. The increase in metabolism could be essential to nutrient redistribution and new tissue development, a strategy the plants adopted to cope with the changed environment.

Our results showed that $4 \%$ of the unigene set responds to external stimulus, while $2 \%$ responds to stress (Fig. 2A). These two catgories form the basis for mining the stressregulated genes. Genes encoding dehydration-induced ERD15 protein (DT083772), late embryogenesis abundant (LEA) protein (DT084384) and other stress-induced proteins were found in these categories. Submergence induced gene, induced by anaerobic stress, was also found in the ESTs sequenced (DT082680). There were also other genes function as scavengers of reactive oxygen species, such as catalase, glutathione S-transferase, and superoxide dismutase. These gene products are needed to maintain the redox homeostasis under abiotic stress. It was reported that overexpression of $\mathrm{H}_{2} \mathrm{O}_{2}$-scavenging enzymes increased the tolerance of plants to abiotic stress[17]. Metallothioneins (MT) are a group of low-molecular-weight (LMW) metal-binding proteins with a high cysteine content that are thought to be involved in metal ion metabolism and detoxification [18]. MT-like transcripts have been reported to be highly up-regulated in response to salt stress in barley $[19,20]$. Type 2 metallothionein (DT083320, DT083023) was present in our database.

In addition, proteins involved in the regulation of signal transduction pathway (Fig 2B) have been categorized separately. In plant cells, calcium functions as a second messenger coupling a wide range of extracellular stimuli to intracellular responses [21]. Calmodulin, one major class of $\mathrm{Ca}^{2+}$ sensor characterized in plants, which was present in the Glycine soja ESTs (DT083725), is involved in stress signal transduction suggested by several lines of evidence [21-23].

Table 2: Comparison of Glycine soja ESTs with those in Glycine max, Arabidopsis and Oryza sativa

\begin{tabular}{|c|c|c|c|c|c|c|}
\hline Database & Number of bp & $\begin{array}{l}\text { Number of } \\
\text { sequences }\end{array}$ & E-value & $\begin{array}{l}\text { Sum of matching } \\
\text { section }\end{array}$ & Matching summary & $\begin{array}{l}\text { Average matching } \\
\text { length }\end{array}$ \\
\hline AGI & $62,362,651$ & 61,603 & Ie-30 & 235 & $\begin{array}{l}\geq 98 \% 9 \\
\geq 90 \% 89\end{array}$ & $\geq 200$ bp \\
\hline GMGI & $37,918,896$ & 63,676 & Ie-30 & 3106 & $\begin{array}{l}\geq 98 \% 1011 \\
\geq 90 \% 2078\end{array}$ & $\geq 200 \mathrm{bp}$ \\
\hline OGI & $93,862,193$ & 89,147 & Ie-30 & 521 & $\begin{array}{l}\geq 98 \% 57 \\
\geq 90 \% 391\end{array}$ & $\geq 200 \mathrm{bp}$ \\
\hline
\end{tabular}


Table 3: The GO categorization of Glycine soja ESTs by biological process, molecular function, and cellular component

\begin{tabular}{|c|c|c|c|}
\hline & Gene Ontology term & Representation & Representation percentage \\
\hline \multirow[t]{15}{*}{ Biological process } & Metabolism & 385 & $69 \%$ \\
\hline & Protein metabolism & 92 & $17 \%$ \\
\hline & Biosynthesis & 79 & $14 \%$ \\
\hline & Nucleic acid metabolism & 44 & $8 \%$ \\
\hline & Catabolism & 24 & $4 \%$ \\
\hline & Oxygen and reactive oxygen species metabolism & 4 & $1 \%$ \\
\hline & Cell growth and/or maintenance & 70 & $13 \%$ \\
\hline & Transport & 37 & $7 \%$ \\
\hline & Stress response & 10 & $2 \%$ \\
\hline & Photosynthesis & 63 & $11 \%$ \\
\hline & Cell communication & 27 & $5 \%$ \\
\hline & Response to external stimulus & 20 & $4 \%$ \\
\hline & Signal transduction & 5 & $1 \%$ \\
\hline & Developmental process & 2 & $<1 \%$ \\
\hline & Cell death & 2 & $<1 \%$ \\
\hline \multirow[t]{18}{*}{ Molecular function } & Binding & 202 & $39 \%$ \\
\hline & ATP bingding & 43 & $8 \%$ \\
\hline & Metal ion binding & 41 & $8 \%$ \\
\hline & Nucleotide binding & 7 & $1 \%$ \\
\hline & Catalytic activity & 197 & $38 \%$ \\
\hline & Transferase activity & 67 & $13 \%$ \\
\hline & Hydrolase activity & 45 & $9 \%$ \\
\hline & Oxidoreductase activity & 38 & $7 \%$ \\
\hline & Kinase activity & 34 & $7 \%$ \\
\hline & Structural molecule activity & 45 & $9 \%$ \\
\hline & Structural constituent of ribosome & 38 & $7 \%$ \\
\hline & Transporter activity & 37 & $7 \%$ \\
\hline & Chaperone activity & 10 & $2 \%$ \\
\hline & Translation regulator activity & 8 & $2 \%$ \\
\hline & Signal transducer activity & 4 & $1 \%$ \\
\hline & Transcription regulator activity & 4 & $1 \%$ \\
\hline & Enzyme regulator activity & 1 & $<1 \%$ \\
\hline & Motor activity & 1 & $<1 \%$ \\
\hline \multirow[t]{2}{*}{ Cellular component } & Intracellular & 332 & $73.3 \%$ \\
\hline & Membrane & 121 & $26.7 \%$ \\
\hline
\end{tabular}

Genes for transcription factors that contain typical DNA binding motifs, such as MYB, bZIP, have been demonstrated to be stress inducible [24]. Transcription factors containing similar domains are present in the Glycine soja ESTs and may be important in regulating the response to salt stress.

\section{Conclusion}

We sequenced 2003 ESTs generated from salinity-treated Glycine soja cDNA library, putatively representing 1071 unigenes. Comparison of Glycine soja ESTs with those of Glycine max revealed the potential to investigate the wild soybean's expression profile using the soybean's gene chip. Through analysis of the ESTs with putative functional annotations, a large number of putative stress-regulated genes were identified. The full-length cDNAs of these genes can be obtained easily and their specific func- tions in salt tolerance can be further investigated using transformation technology in model systems, which will eventually provide new gene targets for the genetic engineering of other crop plants for improved resistance to abiotic stresses. Our results will also facilitate genomic analysis in other plant systems.

\section{Methods}

\section{Plant materials}

Seeds of Glycine soja (50109) were inoculated in halfstrength solid MS medium (pH5.8) in the dark until germination. Plants were grown at $25^{\circ} \mathrm{C}$ in a greenhouse with a photoperiod of $15 \mathrm{~h}$ light/ $9 \mathrm{~h}$ dark. One-monthold seedlings were transferred into $150 \mathrm{mM} \mathrm{NaCl}$ solutions. Equal leaves were sampled at $0.5 \mathrm{~h}, 1 \mathrm{~h}, 3 \mathrm{~h}$ and $6 \mathrm{~h}$ and immediately frozen in liquid nitrogen. Frozen tissues were stored at $-80^{\circ} \mathrm{C}$ until use. 
(A) GO Biological Process

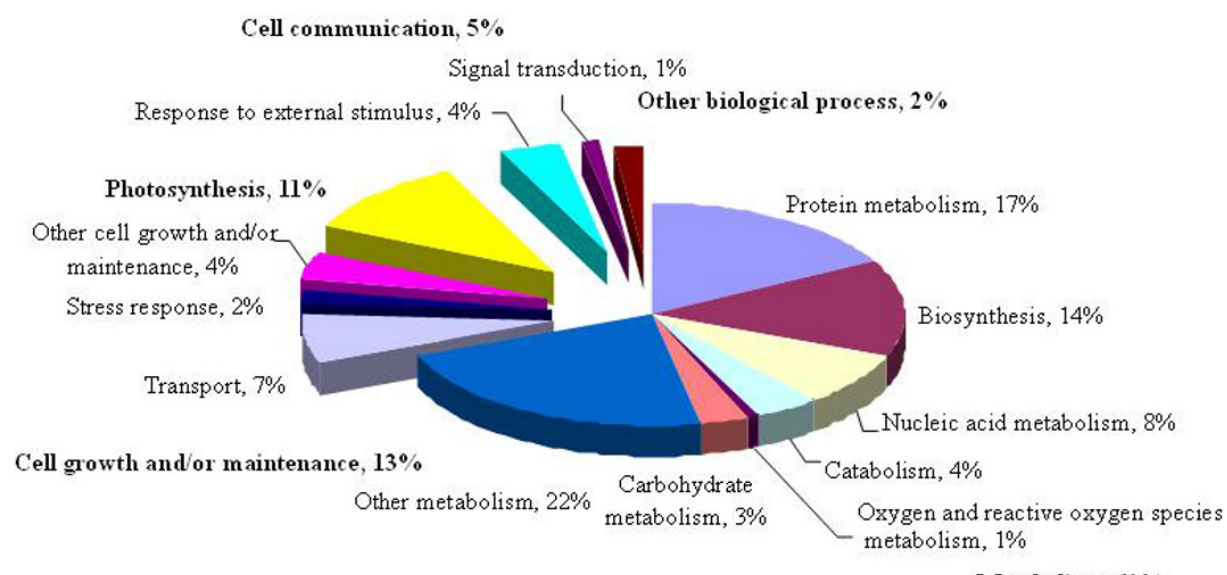

(B) GO Molecular Function

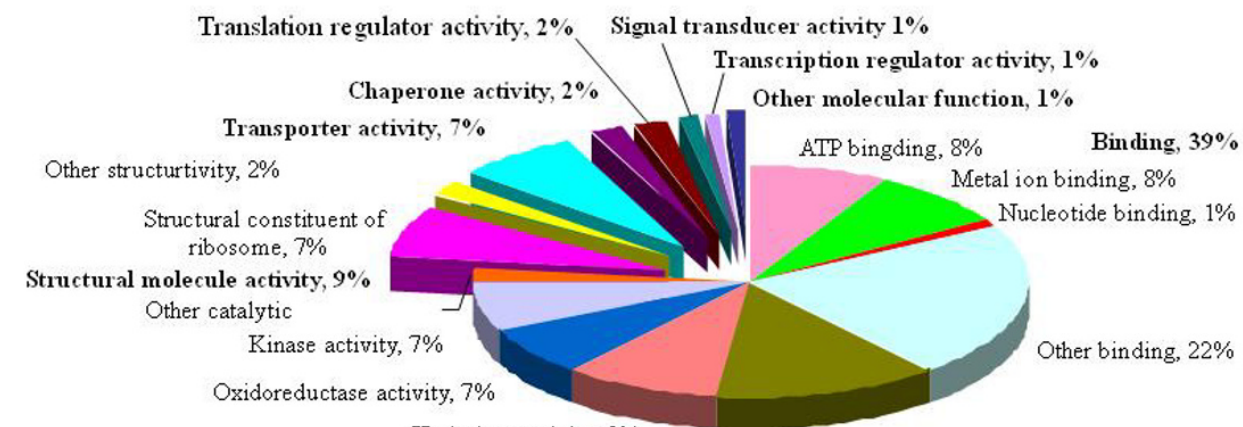

Hydrolase activity, $9 \%$

Transferase activity, $13 \%$

Catalytic activity, $38 \%$

(C) Cellular component

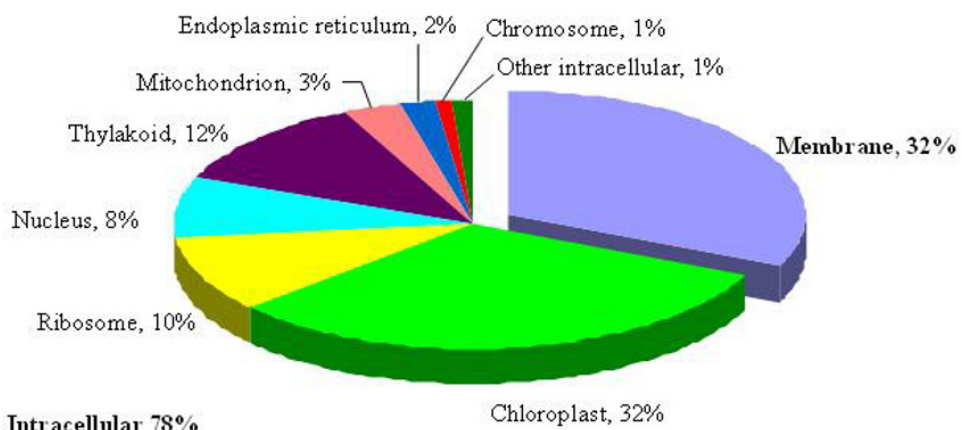

Figure 2

Representation of Gene Ontology (GO) mapping results for Glycine soja non-redundant ESTs. 


\section{RNA preparation and construction of full-length CDNA library}

Total RNA was isolated from plant materials with Trizol (Invitrogen) according to the manufacturer's instructions. The RNA concentration was determined by spectrophotometry, and its integrity was assessed by electrophoresis in $1 \%(\mathrm{w} / \mathrm{v})$ formaldehyde-agarose gels [25].

For the full-length cDNA library, $2 \mu \mathrm{g}$ of mRNA were used for cDNA synthesis using the SMART cDNA synthesis kit (Clontech, Palo Alto, CA, USA) according to the manufacturer's protocol. The resulting double-stranded cDNAs were digested with SfiI and ligated into the SfiI site of $\lambda$ TriplEx2. The phagemids were packaged according to the instruction of Gigapack III Plus-7 packaging extract kit (Stratagene company). The average titer of the libraries was $\sim 2 \times 10^{5} \mathrm{pfu} / \mathrm{ml}$.

\section{Template preparation and DNA sequencing}

Homologous recombination with E. coli BM25.8 was conducted to convert the phage libraries to the plasmid form. 8300 colonies were randomly selected and activated as templates of PCR reactions. The primers are as follows: P5':5'-GGCCATTACGGCCGGG-3'; P3':5'-CCGAGGCGGCCGACATG-3'. PCR was performed for 30 cycles of $30 \mathrm{~s}$ at $94{ }^{\circ} \mathrm{C}, 30 \mathrm{~s}$ at $69^{\circ} \mathrm{C}$ and $2 \mathrm{~min}$ at $72^{\circ} \mathrm{C}$. The PCR products were electrophoresed next to DNA size markers to estimate the molecular sizes of the insert DNAs. The clones with inserted fragments' size $\geq 500$ bp were sequenced by Shanghai Sangon Company.

\section{Sequence analysis}

The trimming process, which included the removal of low-quality sequences, poly(A) tails, ribosomal RNA, and vector regions, was conducted as described by Telles and da Silva [26] with minor modifications. In addition, sequences shorter than 100 bases were not included in the analysis.

The resulting sets of cleaned sequences were assembled into contigs by PHRAP program[27] using the following parameters: minmatch 100, minscore 94.

To assign annotation to contigs, BLASTX was used to search the Uniprot (EBI) with terms from the Gene Ontology Consortium[28] controlled vocabularies. The expectation value (e-value) cutoff for BLASTX was set at $1 e-5$.

In order to survey the similarity between soybean and wild soybean expressed sequences, our set of ESTs was blasted against local installations of GMGI (Glycine max Gene Index, release 12), AGI (Arabidopsis Gene Index, release 12) and OGI (Oryza sativa Gene Index, release 16) from TIGR. The Glycine soja ESTs were also blasted against Arabidopsis CDS from TAIR (release 6) at $1 e-15$. The raw data (cel file) of microarray experiment of Arabidopsis from TAIR (AtGenExpress) were used to identify up-regulated CDS of Arabidopsis response to salt stress. The software RMAExpress (Ben Bolstad) was used to scale/ normalize the raw data.

\section{Authors' contributions}

The first four authors contributed equally to this work. Wei Ji participated in the EST data analysis and drafted the manuscript. Yong Li performed the data analysis and helped to draft the manuscript, and is one of the co-first authors. Jie Li participated in the planning and supervising of the study, and is one of the co-first authors. Cuihong Dai participated in construction of full-length cDNA library and template preparation, and is one of the co-first authors. Yan-ming Zhu participated in the design of the study, and is the corresponding author. All authors read and approved the final manuscript.

\section{Acknowledgements}

This project was jointly sponsored by National Key Basic Research Special Funds, China (2003CCA03500) and National Natural Science Foundation of China (30570990). We thank doctor Dian-jing Guo for critical reading of the manuscript.

\section{References}

I. John Cushman C, Hans Bohnert J: Genomic approaches to plant stress tolerance. Genome studies and molecular genetics, Current Opinion in Plant Biology 2000, 3: I I7-124.

2. Frova C, Caffulli A, Pallavera E: Mapping quantitative trait loci for tolerance to abiotic stresses in maize. J Exp Zool 1999, 282: $164-170$.

3. Cushman JC, Bohnert HJ: Genomics approaches to plant strss. Curr Opin Plant Biol 2000, 3(2): I I 7-I 24.

4. Nuccio ML, Rhodes D, McNeil SD, Hanson AD: Metabolic engineering of plants for osmotic stress resistance. Curr Opin Plant Biol 1998, 2:128-134.

5. Bouchez D, Höfte H: Functional genomics in plants. Plant Physiol 1998, I I 8:725-732.

6. Somerville C, Somerville S: Plant functional genomics. Science 1999, 285:380-383.

7. Alba R, Fei Z, Payton P, Liu Y, Moore SL, Debbie P, Cohn J, D'Ascenzo M, Gordon JS, Rose JK, Martin G, Tanksley SD, Bouzayen M, Jahn MM, Giovannoni J: ESTs, cDNA microarrays, and gene expression profiling: tools for dissecting plant physiology and development. The Plant Journal 2004, 39:697-7।4.

8. Hui Wei, Anik Dhanaraj L, Lisa Rowland J, Yan Fu, Stepen Krebs L, Rajeev Arora: Comparative analysis of expressed sequence tags from cold-acclimated and non-acclimated leaves of Rhododendron catawbiense Michx. Planta . 2005 Jan 27

9. Qiao Yake, Li Guilan, Gao Shuguo, Bi Yanjuan, You Lina, Shi Xiangfu, Zhang Yi: Geographical Distribution and Salt Tolerance of Wild Soybean (G. Soja) in Inshore Regions in ChangLi Hebei Province. Journal of Hebei Vocation Technical Teachers College 200I, I5(2):9-13.

10. Wong CE, Li Y, Whitty BR, Diaz-Camino C, Akhter SR, Brandle JE, Golding GB, Weretilnyk EA, Moffatt BA, Griffith M: Expressed sequence tags from the Yukon ecotype of Thellungiella reveal that gene expression in response to cold, drought and salinity shows little overlap. Plant Molecular Biology 2005, 58:56|-574.

II. Dinah Qutob, Peter Hraber T, Bruno Sobral WS, Mark Gijzen: Comparative Analysis of Expressed Sequences in Phytophthora sojae. Plant Physiology 2000, I 23:243-253.

12. The Arabidopsis Information Resource [http://www.arabidop sis.org] 
13. Berardini TZ, Mundodi S, Reiser L, Huala E, Garcia-Hernandez M, Zhang P, Mueller LA, Yoon J, Doyle A, Lander G, Moseyko N, Yoo D, Xu I, Zoeckler B, Montoya M, Miller N, Weems D, Rhee SY: Functional annotation of the Arabidopsis genome using controlled vocabularies. Plant Physiol 2004, 135:745-755.

14. Preeti A, Mehta K, Sivaprakash M, Parani Venkataraman Gayatri, Ajay Parida K: Generation and analysis of expressed sequence tags from the salt-tolerant mangrove species Avicennia marina (Forsk) Vierh. Theor Appl Genet 2005, I I 0:4 I 6-424.

15. Waditee R, Hibino T, Tanaka Y, Nakamura T, Incharoensakdi A, Hayakawa S, Suzuki S, Futsuhara Y, Kawamitsu Y, Takabe T, Takabe T: Functional characterization of betaine/praline transporters in betaine-accumulating mangrove. J Biol Chem 2002, 277: $18373-18382$.

16. Huh GH, Damez B, Matsumoto TK, Reddy MP, Rus AM, Ibeas Jl, Narasimhan ML, Bressan RA, Hasegawa PM: Salt causes ion disequilibriuminduced programmed cell death in yeast and plants. Plant J 2002, 29:649-659.

17. Yan Wang J, Tissue D, Holaday AS, Allen R, Zhang H: Photosynthesis and seed production under water deficit conditions in transgenic tobacco plants that overexpress an Arabidopsis ascorbate peroxidase gene. Crop Sci 2003, 43:1477-I 483.

18. Hall JL: Cellular mechanisms for heavy metal detoxification and tolerance. J Exp Bot 2002, 53: I- II.

19. Ozturk ZN, Talame V, Deyholos M, Michalowski CB, Galbraith DW Gozukirmizi N, Tuberosa R, Bohnert HJ: Monitoring large-scale changes in transcript abundance in droughtand salt-stressed barley. Plant Mol Biol 2002, 48:55 I-573.

20. Bausher M, Shatters R, Chaparro J, Dang P, Hunter W, Niedz R: An expressed sequence tag (EST) set from Citrus sinensis $L$. Osbeck whole seedling and the implications of further perennial source investigations. Plant Sci 2003, 165:4I5-422.

21. Snedden WA, Fromm H: Calmodulin as a versatile calcinm signal transducer in plants. New Phytol 200I, I 5 I:35-36.

22. Zhu JK: Genetic analysis of plant salt tolerance using Arabidopsis. Plant Physiol 2000, I 24:94I-948.

23. Luan S, Kudla. J, Rodriguez-Concepcion M, Yalovsky S, Gruissem W: Clamodulins and calcineurin-B like proteins: Calcium sensors for specific signal response coupling in plants. Plant Cell 2002, I 4:S389-S400.

24. Zhu JK: Salt and drought stress signal transduction in plants. Annu Rev Plant Biol 2002, 53:247-273.

25. Sambrook J, Fritsch EF, Maniatis T: Molecular Cloning: A Laboratory Manual. Cold Spring Harbor Laboratory Press, Cold Spring Harbor, NY; 1989.

26. Telles GP, da Silva FR: Trimming and clustering sugarcane ESTs. Genet Mol Biol 200I, 24:17-23.

27. Laboratory of PHIL GREEN [http://www.phrap.org]

28. Gene Ontology Home [http://www.geneontology.org]

\section{Publish with Bio Med Central and every scientist can read your work free of charge}

"BioMed Central will be the most significant development for disseminating the results of biomedical research in our lifetime. "

Sir Paul Nurse, Cancer Research UK

Your research papers will be:

- available free of charge to the entire biomedical community

- peer reviewed and published immediately upon acceptance

- cited in PubMed and archived on PubMed Central

- yours - you keep the copyright
BioMedcentral 